\title{
Left atrial appendage clip occlusion: Early clinical results
}

\author{
Sacha P. Salzberg, MD, ${ }^{\mathrm{a}}$ Andre Plass, MD, ${ }^{\mathrm{a}}$ Maximillian Y. Emmert, MD, ${ }^{\mathrm{a}}$ Lotus Desbiolles, MD, \\ Hatem Alkadhi, MD, ${ }^{b}$ Jurg Grünenfelder, $\mathrm{MD},{ }^{\mathrm{a}}$ and Michele Genoni, ${ }^{\mathrm{M}}{ }^{\mathrm{a}}$
}

Objective: Atrial fibrillation puts patients at significant risk for embolic stroke originating from the left atrial appendage. Few means are available for safe, effective, and durable left atrial appendage occlusion. A new clip device was evaluated with regard to safety and effectiveness for epicardial left atrial appendage occlusion.

\begin{abstract}
Methods: Patients with atrial fibrillation undergoing elective cardiac surgery through a median sternotomy were enrolled for concomitant epicardial clip placement. Early postoperative and 3-month follow-up computed tomography studies were used to assess clip stability and left atrial appendage perfusion.
\end{abstract}

Results: From September 2007 to December 2008, 34 patients underwent successful clip placement. No devicerelated complications occurred. Operative mortality was $8.8 \%$ and not study or device related. Deployment was rapid, and left atrial appendage occlusion was confirmed by intraoperative transesophageal echocardiography in all patients. In addition to excellent clinical outcomes (no stroke/transient ischemic attack), serial computed tomography demonstrated stable clip location and appendage perfusion at 3 months in all patients.

Conclusion: Safe, effective, and durable left atrial appendage occlusion can easily be achieved with this new clip. Further trials are necessary to evaluate the role of the left atrial appendage occlusion in stroke prevention. (J Thorac Cardiovasc Surg 2010;139:1269-74)

Atrial fibrillation (AF) is a common cardiac arrhythmia affecting many patients and is associated with increased mortality independently of other cardiac conditions and risk factors. ${ }^{1,2}$ The prevalence of AF and AF-related hospital admissions is constantly increasing. ${ }^{3}$ Thromboembolic origin in $\mathrm{AF}$ is often linked to the left atrial appendage (LAA). ${ }^{4}$ The gold standard for medical management of patients with AF remains oral anticoagulation with warfarin. ${ }^{5,6}$ Percutaneous device occlusion of the LAA remains challenging. ${ }^{7}$ The recent Protect AF trial has nevertheless showed noninferiority of LAA transcatheter device closure to oral anticoagulation in patients with $\mathrm{AF}^{8}{ }^{8}$ Surgical LAA occlusion is recommended in the latest AHA/ACC/ESC guidelines for surgical mitral valve disease ${ }^{6}$ but also lacks the desired effectiveness of an ideal therapy. ${ }^{9}$ With the advent of minimally invasive techniques to address $\mathrm{AF}$, strategies to obtain LAA occlusion remain challenging and are

From the Clinic for Cardiovascular Surgery ${ }^{\mathrm{a}}$ and Institute of Diagnostic Radiology, ${ }^{\mathrm{b}}$ University Hospital Zurich, Switzerland.

Disclosures: S.P.S. reports consulting fees and grant support from Atricure. This study was supported by a grant from Atricure, the manufacturer of the LAA clip. All ablation technology was purchased as part of standard clinical care. The authors had full control of the design of the study, methods used, outcomes parameters, analysis of data, and production of this article. This research was funded with an unrestricted research grant from Atricure Inc. H.A. and L.D. have been supported by the National Center of Competence in Research, Computer Aided and Image Guided Medical Interventions of the Swiss National Science Foundation. The trial is registered at www.ClinicalTrials.gov, Reference: NCT00567515.

Received for publication March 12, 2009; revisions received May 20, 2009; accepted for publication June 10, 2009; available ahead of print Nov 2, 2009.

Address for reprints: Sacha P. Salzberg, MD, Clinic for Cardiovascular Surgery, University Hospital Zurich, Rämistrasse 100, CH - 8091 Zurich (E-mail: sacha. salzberg@gmail.com).

$0022-5223 / \$ 36.00$

Copyright (C) 2010 by The American Association for Thoracic Surgery

doi:10.1016/j.jtcvs.2009.06.033 often traumatic to the LAA, even in expert hands. ${ }^{7}$ In addition, few data are available to determine the role of LAA occlusion in stroke prevention. ${ }^{10}$ This first human trial was designed to evaluate safety and effectiveness of a new clip $^{11}$ used for LAA occlusion in patients with AF undergoing cardiac surgery.

\section{MATERIALS AND METHODS}

From September 2007 to December 2008, patients were enrolled in this trial at the University Hospital Zurich. Primary inclusion criterion was elective cardiac surgery in adult patients with AF for whom an ablation procedure was planned. Patients undergoing a reoperation, with a known thrombus in the LAA, from the intensive care unit, with a history of pericarditis, who had a recent myocardial infarction ( $<90$ days), and with a known allergy to the devices component were not allowed to participate (exclusion criteria). Intraoperative transesophageal echocardiography (TEE) was used to rule out LAA thrombus at baseline (exclusion criteria) and assess LAA perfusion at the end of the procedure. Patients returned to the University Hospital Zurich for serial follow-up after 3 months and yearly thereafter up to 3 years after surgery. Clinical follow-up included clinical status, laboratory examination, electrocardiogram, chest radiograph and computed tomography (CT) workup.

Research was conducted in accordance with the ethical standards of the responsible committee on human experimentation (institutional and national) and the Helsinki Declaration of 1975 , as revised in $2000 .^{12}$ All patients gave informed written consent. The trial is registered at www. ClinicalTrials.gov (Reference: NCT00567515).

\section{Device Description}

The LAA clip system consists of a self-closing, sterile, implantable clip with a reusable deployment tool (Figure 1, $A$ ). The device is applied epicardially (Figure $1, B$ ) and has been previously described. ${ }^{11,13}$ In addition, a disposable selection guide is used to choose the appropriate clip size. For human use, the clip is available in $4 \operatorname{sizes~}(35 \mathrm{~mm}, 40 \mathrm{~mm}, 45 \mathrm{~mm}$, and $50 \mathrm{~mm})$. When closed, the clip applies uniform pressure over the length of the 2 parallel branches to ensure consistent, reproducible, and secure occlusion of the LAA. 


\section{Abbreviations and Acronyms \\ $\mathrm{AF}=$ atrial fibrillation \\ $\mathrm{CT}=$ computed tomography \\ LAA $=$ left atrial appendage \\ TEE $=$ transesophageal echocardiography}

\section{Computed Tomography Protocol}

All scans were performed using a dual-source CT scanner system with nonionic contrast medium, standard scanning, and image reconstruction parameters. ${ }^{14}$ LAA neck diameter was preoperatively measured on curved multiplanar reformations through the LAA (Figure 2, $A, B$ ). The LAA patency was visually analyzed by 2 experienced independent readers in consensus. Clip stability was assessed using 2 different measures: (1) distance from the ostium of the circumflex artery to each end of the clip (Figure 2, C) and (2) angle between a line drawn along the posterior tips of the transverse processes of the spine and the long axis of the clip (Figure 2,D). Table 1 summarizes the CT findings.

\section{Statistical Analysis}

The Kruskal-Wallis test was used to test for significant changes between the parameters of average heart rate and heart rate variability during scanning, as well as the clip location (ie, distances and angles), LA diameters, and LV function parameters across the CT examinations at different dates. Statistical analysis was performed using commercially available software (SPSS, release 15.0, Chicago, Ill).

\section{RESULTS}

\section{Summary}

A total of 34 patients underwent cardiac surgery with concomitant LAA clip placement. Patients' median age was 71 \pm 10 years, and $58 \%$ were men. Mean preoperative logistic EuroScore was $10 \% \pm 3 \%$, and mean left ventricular function was $58 \% \pm 14 \%$. Classification of $\mathrm{AF}$ was paroxysmal $(\mathrm{n}=14,42 \%)$, persistent $(\mathrm{n}=8,23 \%)$, or permanent $(\mathrm{n}=12,35 \%)$; the mean duration of AF before surgery was $4 \pm 1.5$ years. Procedures performed were mitral valve repair $(\mathrm{n}=11)$, mitral and tricuspid valve repair $(2)$, mitral repair and aortic valve replacement (3), aortic valve replacement with mitral and tricuspid repair (1), aortic valve replacement (5), composite graft (1), coronary artery bypass grafting (7), and combined valve and coronary artery bypass grafting (4). All patients underwent bipolar radiofrequency pulmonary vein isolation off pump, or if on-pump, before aortic crossclamping with intraoperative conduction block confirmation. In patients with paroxysmal AF addressed for isolated myocardial revascularization, a complete offpump approach was used $(n=5)$. Patients requiring an aortic valve procedure underwent on-pump pulmonary vein isolation $(n=8)$. In the presence of persistent or permanent $\mathrm{AF}$, cardiopulmonary bypass was used, and a complete left atrial lesion set was performed $(n=21,62 \%)$. Left atrial lesions included a posterior connecting lesions to connect the epicardial pulmonary vein lesions, one connecting lesion to the LAA before clip placement and one line from the

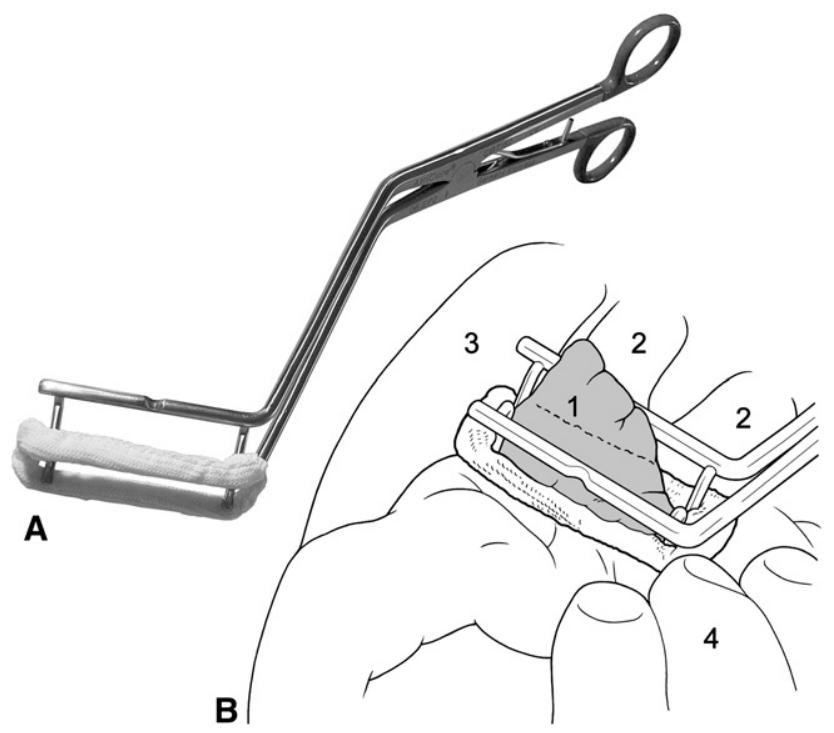

FIGURE 1. LAA clip, deployment tool, and deployment. A, Reusable Miltex deployment tool as it was used in all cases. LAA clip is loaded onto the jaws of this tool. B, LAA mobilized within the clip (1), right pulmonary veins (2), and pulmonary artery (3), and operator's hand (4) gently mobilizing the heart to demonstrate the LAA and allow placement of the clip with the left hand.

atriotomy down to the mitral valve annulus. If a history of atrial flutter was present $(n=7)$, additional right-sided lesions were performed.

Operative mortality occurred in 3 patients $(8.8 \%)$. Cause of death was iatrogenic lung bleed after chest tube injury (postoperative day 1), acute postoperative hepatic failure (postoperative day 16), and aortic tear at aortotomy suture line (postoperative day 20). There was 1 additional death after discharge that resulted from over-anticoagulation (international normalized ratio, 4.4) and subsequent outof-hospital pericardial tamponade (postoperative day 24). Autopsy, institutional, and external review excluded any link to the device or study participation.

\section{Clip Placement}

TEE confirmed the absence of spontaneous echo contrast in all patients (exclusion criteria), as also seen on baseline CT scans. For clip placement, the heart was mobilized (Figure 1) to develop the base of the LAA, which was then assessed with the selection guide. Once the clip was loaded into the reusable deployment tool, while still mobilizing the heart, the primary surgeon placed the clip on the LAA, which was gently mobilized by the first assistant with an atraumatic forceps. When judged satisfactory, located at the base of the LAA, transversally to the roof of the left atrium, the clip was deployed (Figure 1, B). When performing a mitral valve replacement, the clip was applied before inserting the prosthesis. In all other cases with cardiopulmonary bypass, the clip was applied just before opening the aortic crossclamp. In the 

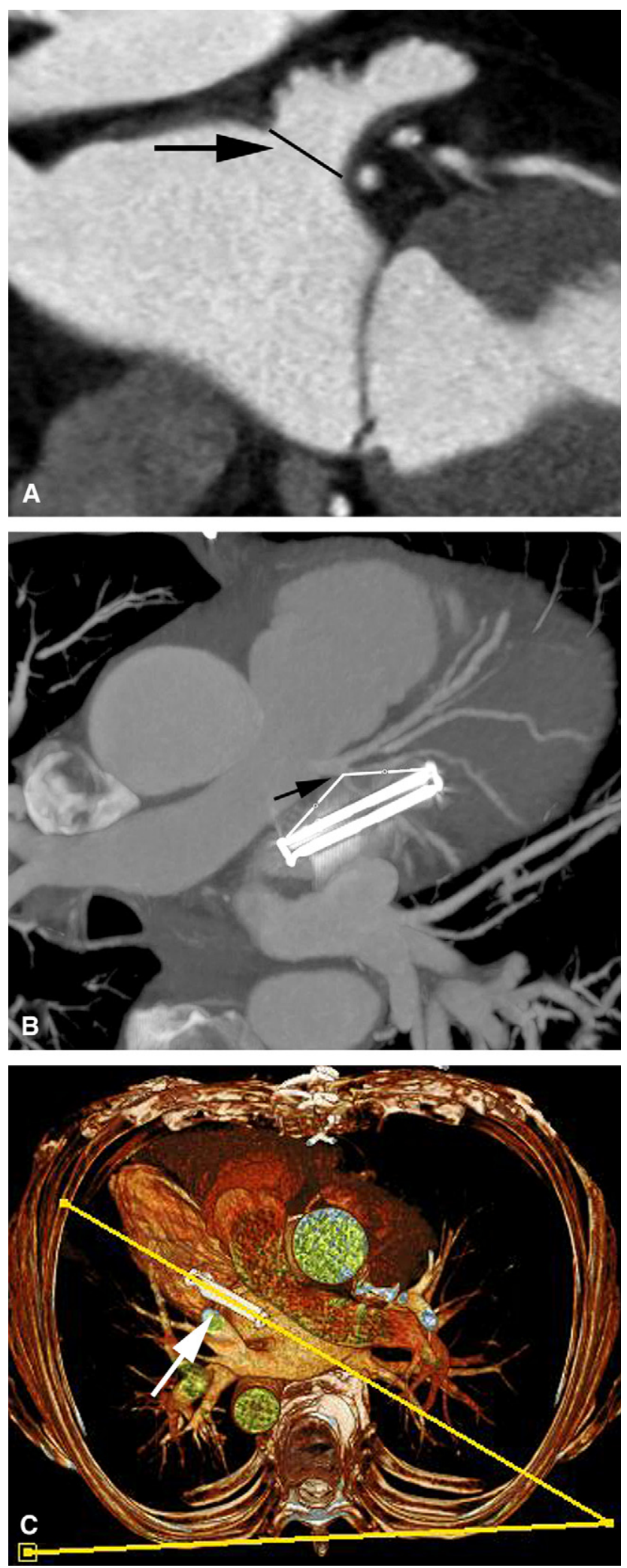

FIGURE 2. CT imagery. A, Curved multiplanar CT reformation demonstrating the plane for measurements of the LAA neck diameter (arrow to black line). B, Oblique-transverse thick maximum intensity projection $\mathrm{CT}$ images showing the 2 distance measurements (arrow to thin white lines) off-pump setting, the clip was applied after myocardial revascularization was completed to ensure sufficient coronary perfusion during cardiac mobilization. No clip repositioning was necessary. In all patients, satisfactory placement at the base of the LAA was achieved in a single attempt and swiftly. The pericardium was closed in all. Postoperatively, TEE confirmed LAA occlusion in all patients. Procedural success rate was $100 \%$.

\section{Postoperative Course}

In regard to the device or study participation, no complications occurred. Anticoagulation and platelet aggregation were managed according to standard clinical practices, that is, all patients received Coumadin and Amiodarone for 6 months until sinus rhythm was documented on 24-hour Holter electrocardiogram. Patients were sent to the regular ward, at which time the first follow-up CT was performed $(\mathrm{n}=$ 30). Chest radiographs in both anteroposterior and lateral views $(\mathrm{n}=30)$ were used to assess clip localization. A patient who had received a kidney transplant 5 years previously did not undergo any follow-up CT evaluation. In 3 of the 4 patients with fatal outcomes, no follow-up CT was performed. In 2 of these patients, TEE performed on the intensive care unit demonstrated no LAA perfusion, and chest radiographs showed stable clip localization.

\section{Computed Tomography Findings}

Despite AF at baseline ( $\mathrm{n}=19,56 \%$ of patients) and high heart rate variability across all scans during scanning, the image quality of all examinations was diagnostic, that is, all measurements could be made in all patients. LAA neck diameter was on average $1.9 \mathrm{~cm}$ at its most narrow point, considered the "landing zone" of the clip (Table 1). After surgery, in all serial CT scans the LAA was completely occluded, and the clip appeared to remain stable (Figure 3). All measurements (ie, distances and angles) showed no significant changes across the serial examination dates (Table 1). Both left atrial and left ventricular function showed no significant changes when compared (Table 1).

\section{Follow-up}

Clinical follow-up was $100 \%$ complete at 3 months $(\mathrm{n}=30)$. In several patients, no follow-up CT was performed, in which case serial chest radiographs were used to assess clip stability. Cardiac rhythm at 3 month follow-up was regular sinus rhythm in 21 patients $(70 \%), \mathrm{AF}$ in 6 patients (20\%, all had permanent AF before surgery),

from the ostium of the circumflex artery to both ends of the LAA clip. C, Volume-rendered CT image demonstrating the measurement of the orientation of the LAA clip. The angle was measured between 2 lines drawn along the posterior tips of the transverse processes and along the LAA clip (arrow). 
TABLE 1. Computed tomography findings before surgery, before discharge, and at 3-month follow-up

\begin{tabular}{|c|c|c|c|c|}
\hline $\begin{array}{c}\text { Time point } \\
\mathbf{N} \\
\end{array}$ & $\begin{array}{c}\text { Baseline } \\
34 \\
\end{array}$ & $\begin{array}{c}\text { Before discharge } \\
30 \\
\end{array}$ & $\begin{array}{c}\text { 3-Month follow-up } \\
26 \\
\end{array}$ & $P$ value* \\
\hline Heart rate (beats/min) & $68 \pm 11(52-103)$ & $78 \pm 15(59-113)$ & $71 \pm 14(58-100)$ & $<.05$ \\
\hline Variability & $10 \pm 8(1-27)$ & $9 \pm 8(1-33)$ & $5 \pm 4(1-12)$ & .21 \\
\hline LAA patency & Patent, no thrombus & None & None & / \\
\hline LAA neck $(\mathrm{cm})$ & $1.9 \pm 0.4(1.1-2.8)$ & l & / & l \\
\hline \multicolumn{5}{|l|}{ LAA clip location } \\
\hline First distance to CX (mm) & / & $18 \pm 5(9-29)$ & $17 \pm 4(12-29)$ & .49 \\
\hline Second distance to $\mathrm{CX}(\mathrm{mm})$ & l & $32 \pm 8(20-49)$ & $34 \pm 8(20-47)$ & .77 \\
\hline Angle (degrees) & l & $39 \pm 22(11-96)$ & $41 \pm 16(12-70)$ & .51 \\
\hline \multicolumn{5}{|l|}{ LA diameter (mm) } \\
\hline LA systolic & $48 \pm 14(27-90)$ & $44 \pm 9(28-68)$ & $47 \pm 9(33-68)$ & .65 \\
\hline LA diastolic & $45 \pm 15(23-88)$ & $41 \pm 10(20-64)$ & $43 \pm 9(29-63)$ & .46 \\
\hline \multicolumn{5}{|l|}{ LV dimensions } \\
\hline ESV & $89 \pm 57(27-285)$ & $82 \pm 57(22-297)$ & $87 \pm 52(31-230)$ & .89 \\
\hline EDV & $163 \pm 74(82-410)$ & $148 \pm 75(63-410)$ & $166 \pm 63(92-345)$ & .44 \\
\hline SV & $74 \pm 27(23-139)$ & $66 \pm 29(22-130)$ & $72 \pm 32(15-134)$ & .60 \\
\hline \multicolumn{5}{|l|}{ LV function } \\
\hline $\mathrm{CO}(\mathrm{L} / \mathrm{min})$ & $5.1 \pm 2.0(2.5-8.7)$ & $5.0 \pm 2.3(1.7-9.8)$ & $5.5 \pm 1.9(1.6-8.9)$ & .61 \\
\hline $\mathrm{EF}(\%)$ & $47 \pm 14(25-69)$ & $47 \pm 15(22-69)$ & $50 \pm 16(22-74)$ & .78 \\
\hline Myocardial mass (g) & $181 \pm 49(112-270)$ & $184 \pm 52(104-277)$ & $170 \pm 55(22-236)$ & .87 \\
\hline
\end{tabular}

$L A A$, Left atrial appendage; $C X$, circumflex coronary artery; $L A$, left atrium; $L V$, left ventricle; $E S V$, end-systolic volume; $E D V$, end-diastolic volume; $S V$, stroke volume; $C O$, cardiac output; $E F$, ejection fraction. *Kruskal-Wallis test.

de novo atrial flutter in 3 patients $(10 \%)$, and pacemaker induced in 2 patients $(6 \%)$. At follow-up, no stroke or transient ischemic attack had occurred in any patients (Table 2).

\section{DISCUSSION}

We report the first human application of a new epicardial clip for concomitant LAA occlusion during cardiac surgery in patients with AF. Clip placement through a median sternotomy was performed rapidly and in one attempt. There were no clip-related complications. CT provided proof of absence of LAA thrombus (baseline) and demonstrated durability and stability of clip occlusion after surgery and over time.

As part of the classic cut-and-sew Maze procedure, initially described by James Cox's group, ${ }^{15}$ surgical excision of both atrial appendages was first reported. After a mean follow-up of more than 5 years, only 1 patient in more than 200 had a stroke, despite the fact that most patients were not taking anticoagulation ${ }^{15}$; however, the causality of an effective procedure restoring sinus rhythm versus exclusion of atrial appendages remains uninvestigated. Since then, surgical epicardial occlusion was evaluated in the LAAOS trial ${ }^{16}$ in patients undergoing coronary artery bypass grafting with increased risk of stroke (CHADS score $>2$ ). Seventy-seven patients were randomized to LAA occlusion, by staples or suture, or control. During surgery, there were 9 LAA injuries that were readily repaired. Predischarge LAA occlusion was effective in $45 \%$ using sutures and in $72 \%$ using a stapler. These results are similar to other reports, ${ }^{17}$ highlighting the main challenge faced when attempting to eliminate the LAA safely from the circulation. This is stressed by a recent echocardiographic follow-up trial $^{9}$ on 137 patients who underwent LAA closure by excision $(\mathrm{n}=52)$ and exclusion by stapler or suture $(\mathrm{n}=85)$ during cardiac surgery. In addition to an impressive learning curve affecting outcomes, the authors demonstrated only $40 \%$ of successful closures. Furthermore, LAA thrombus was found in $41 \%$ of patients with unsuccessful LAA exclusion versus none with excision. After 6 months, 6 patients with successful LAA closure $(11 \%)$ and 12 patients with unsuccessful closure (15\%) had evidence of stroke/transient ischemic attack. The authors concluded that there is a high occurrence of unsuccessful surgical LAA closure with severe neurologic consequences. The present study obtained $100 \%$ effective LAA occlusion with no learning curve, complications, or neurologic events during follow-up. Effective off-pump clip application was performed in 5 patients $(15 \%)$ with paroxysmal AF requiring pulmonary vein isolation and off-pump coronary artery bypass grafting. In this setting, this device shows true promise, because LAA injury, especially in a minimally invasive setting, can be a serious complication. From preclinical ${ }^{11,13}$ and current experience, LAA injury during clip placement was never an issue.

Catheter-based approaches to closing the LAA have been reported but remain limited because of the inherent limitations of this approach. The Protect AF trial provides the first real evidence suggesting that closure of the LAA provides an alternative strategy to oral anticoagulation for stroke prevention in patients with nonvalvular AF. However, the 

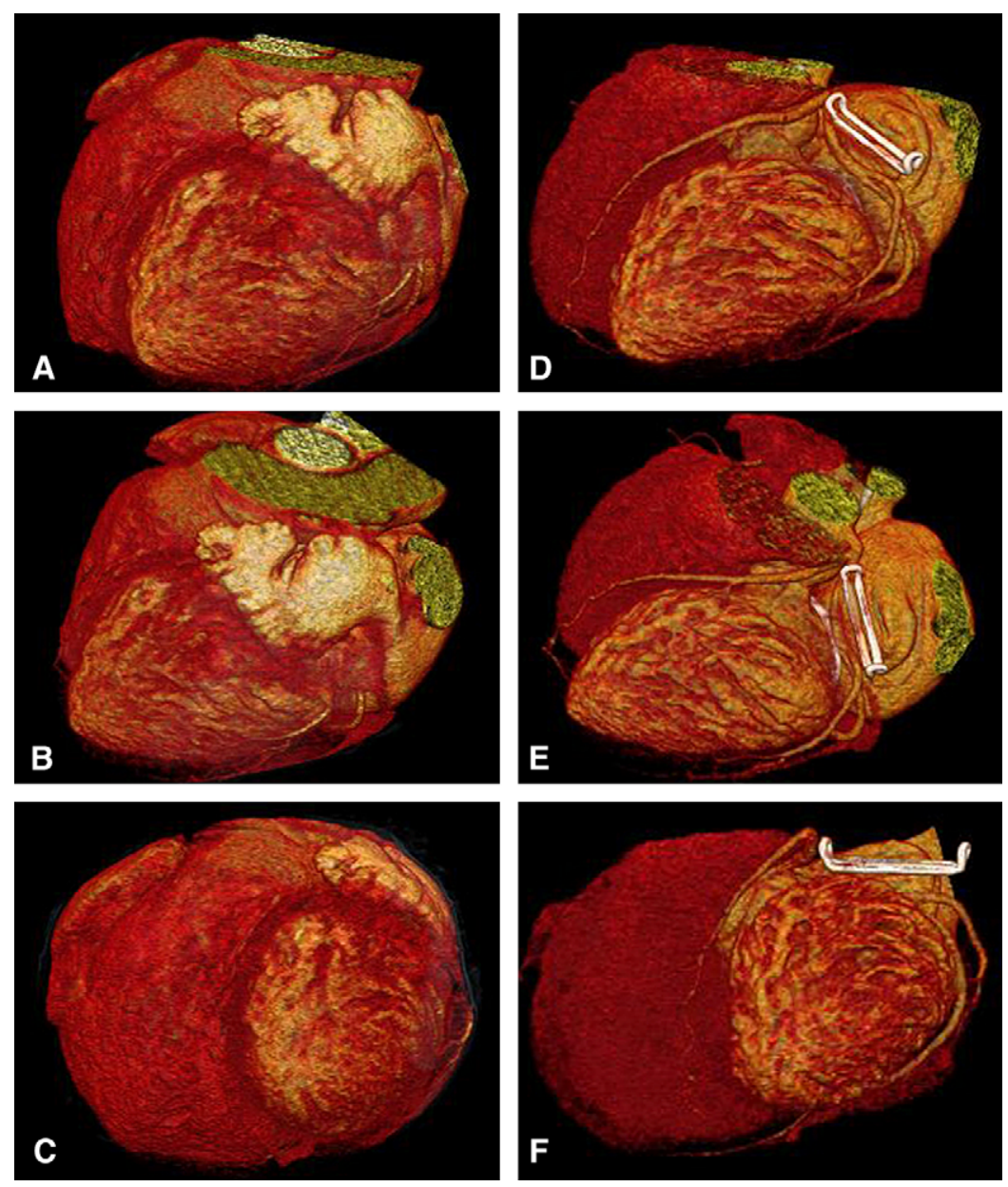

FIGURE 3. Multiple views to the heart in 3-dimensional volume showing clip placement technique preoperatively (A-C) and postoperatively (D-F).

limitations of this approach are once again highlighted by this trial as well. ${ }^{8}$ The authors conclude that a higher rate of adverse events mainly resulted of peri-procedural complications, as seen by other investigators. ${ }^{18}$ In addition, we believe that anatomic considerations such as the highly individual variability of the left atrial aperture at the base of the LAA, ${ }^{19}$ which we also documented in our preoperative CT imaging, may limit efficacious LAA occlusion from within. We encountered a very high individual anatomic variability of the LAA. It also appears that the CT measurements of the LAA neck were not at all correlated with the final intraoperative clip size chosen with the measuring device. This is mainly due to the variability of the neck, which is considered the landing zone for the clip. The dimension of the LAA neck in our series was on average $1.9 \mathrm{~cm}$ in diameter, varying from 0.8 to $2.9 \mathrm{~cm}$ (Table 1 ). In a recent series on LAA anatomy in patients with AF studied by magnetic resonance imaging, Heist and colleagues ${ }^{19}$ concluded that a significant heterogeneity in LAA size and dimension was present. The advantages of a standard epicardial approach for LAA closure are clear. The current clip is available in 4 sizes. In our experience, we used the 2 smallest clip sizes ( 35 and $40 \mathrm{~mm}$ ) in most cases. The positioning of the clip is the crucial part of the procedure, because it needs to be located as low as possible in the region of the LAA neck on the roof of the left atrium. In addition, we also

TABLE 2. Clinical follow-up data

\begin{tabular}{lcccc}
\hline & Baseline & Discharge & $\mathbf{3}$ Mo & 12 Mo \\
N (\%) & $\mathbf{3 4}$ & $\mathbf{3 0}$ & $\mathbf{3 0}(\mathbf{1 0 0})$ & $\mathbf{2 2}(\mathbf{7 3})^{*}$ \\
\hline Cardiac rhythm: & & & & \\
$\quad$ Sinus rhythm & $15(44)$ & $18(60)$ & $21(70)$ & $17(77)$ \\
Atrial & $19(56)$ & $12(40)$ & $6(20)$ & $4(18)$ \\
$\quad$ fibrillation & & & & \\
Atrial flutter & $7 \dagger(21)$ & & $3(10)$ & \\
Pacemaker & & $2(0.6)$ & $2(0.6)$ & $1(5)$ \\
Medications: & & & & \\
AAD $\ddagger$ & $21(62)$ & $29(97)$ & $28(93)$ & $10(45)$ \\
Coumadin & $15(44)$ & $27(90)$ & $22(73)$ & $11(50)$ \\
Clip stable $\S$ & $34(100)$ & $30(100)$ & $30(100)$ & $22(100)$ \\
\hline
\end{tabular}

$A A D$, Antiarrhythmic medication. *Follow-up not complete. †History of. ‡ॄBetablocker or amiodarone. §On chest radiograph and/or computed tomography. 
conducted a downsizing strategy when choosing the clip according to the measuring tool. We believe this minimized the surface of contact of this foreign body with the roof of the left atrium, which may have had a protective influence on outcomes after ablation procedures for AF. Our results compare well with those in the current literature in a dedicated AF setting. In our experience, LAA clip occlusion did not significantly affect LA diameters and left ventricular function, because these remained constant over time. Patients' well-being was not affected by trial participation.

\section{LIMITATIONS}

Because this was a pilot trial, no controls were enrolled. The trial was not powered to assess stroke prevention.

\section{CONCLUSIONS}

LAA clip occlusion is a safe and effective new therapy for patients with AF. Stroke prevention by LAA occlusions offers a new option for these patients. ${ }^{8}$ Thoracoscopic approaches, with or without an ablation procedure, might provide a new indication for cardiac surgeons. Further clinical trials are necessary to establish this new approach.

\section{References}

1. Go AS, Hylek EM, Phillips KA, Chang Y, Henault LE, Selby JV, et al. Prevalence of Diagnosed Atrial Fibrillation in Adults: National Implications for Rhythm Management and Stroke Prevention: the AnTicoagulation and Risk Factors In Atrial Fibrillation (ATRIA) Study. JAMA. 2001;285:2370-5.

2. Benjamin EJ, Wolf PA, D'Agostino RB, Silbershatz H, Kannel WB, Levy D. Impact of atrial fibrillation on the risk of death: the Framingham Heart Study. Circulation. 1998;98:946-52.

3. Nieuwlaat R, Prins MH, Le Heuzey J-Y, Vardas PE, Aliot E, Santini M, et al. Prognosis, disease progression, and treatment of atrial fibrillation patients during 1 year: follow-up of the Euro Heart Survey on Atrial Fibrillation. Eur Heart J. 2008;29:1181-9.

4. Frost L, Engholm G, Johnsen S, Moller H, Husted S. Incident stroke after discharge from the hospital with a diagnosis of atrial fibrillation. Am J Med. 2000;108:36-40.

5. Lee AM, Melby SG, Damiano RJ Jr. The surgical treatment of atrial fibrillation. Surg Clin North Am. 2009;89:1001-20, x-xi.

6. Fuster V, Rydén LE, Cannom DS, Crijns HJ, Curtis AB, Ellenbogen KA, et al. ACC/AHA/ESC 2006 Guidelines for the Management of Patients With Atrial Fibrillation-Executive Summary: A Report of the American College of Cardiol-
ogy/American Heart Association Task Force on Practice Guidelines and the European Society of Cardiology Committee for Practice Guidelines (Writing Committee to Revise the 2001 Guidelines for the Management of Patients With Atrial Fibrillation) Developed in Collaboration With the European Heart Rhythm Association and the Heart Rhythm Society. J Am Coll Cardiol. 2006; 48:854-906.

7. Syed TM, Halperin JL. Left atrial appendage closure for stroke prevention in atrial fibrillation: state of the art and current challenges. Nat Clin Pract Cardiovasc Med. 2007;4:428-35.

8. Holmes DR, Reddy VY, Turi ZG, Doshi SK, Sievert H, Buchbinder M, Mullin CM, Sick P, PROTECT AF Investigators. Percutaneous closure of the left atrial appendage versus warfarin therapy for prevention of stroke in patients with atrial fibrillation: a randomised non-inferiority trial. Lancet. 2009;374: 534-42.

9. Kanderian AS, Gillinov AM, Pettersson GB, Blackstone E, Klein AL. Success of surgical left atrial appendage closure: assessment by transesophageal echocardiography. J Am Coll Cardiol. 2008;52:924-9.

10. Damiano RJ Jr, Schuessler RB, Voeller RK. Surgical treatment of atrial fibrillation: a look into the future. Semin Thorac Cardiovasc Surg. 2007; 19:39-45.

11. Salzberg SP, Gillinov AM, Anyanwu A, Castillo J, Filsoufi F, Adams DH. Surgical left atrial appendage occlusion: evaluation of a novel device with magnetic resonance imaging. Eur J Cardiothorac Surg. 2008;34:766-70.

12. World Medical Association Declaration of Helsinki. ethical principles for medical research involving human subjects. JAMA. 2000;284:3043-5.

13. Fumoto H, Gillinov AM, Ootaki Y, Akiyama M, Saeed D, Horai T, et al. A novel device for left atrial appendage exclusion: the third-generation atrial exclusion device. J Thorac Cardiovasc Surg. 2008;136:1019-27.

14. Leschka S, Scheffel H, Desbiolles L, Plass A, Gaemperli O, Valenta I, et al. Image quality and reconstruction intervals of dual-source CT coronary angiography: recommendations for ECG-pulsing windowing. Invest Radiol. 2007;42: 543-9.

15. Prasad SM, Maniar HS, Camillo CJ, Schuessler RB, Boineau JP, Sundt TM, et al. The Cox maze III procedure for atrial fibrillation: long-term efficacy in patients undergoing lone versus concomitant procedures. J Thorac Cardiovas Surg. 2003;126:1822-7.

16. Healey JS, Crystal E, Lamy A, Teoh K, Semelhago L, Hohnloser SH, et al. Left Atrial Appendage Occlusion Study (LAAOS): Results of a randomized controlled pilot study of left atrial appendage occlusion during coronary bypass surgery in patients at risk for stroke. Am Heart J. 2005;150:288-93.

17. Blackshear JL, Johnson WD, Odell JA, Baker VS, Howard M, Pearce L, et al. Thoracoscopic extracardiac obliteration of the left atrial appendage for stroke risk reduction in atrial fibrillation. $J$ Am Coll Cardiol. 2003;42:1249.

18. Ostermayer SH, Reisman M, Kramer PH, Matthews RV, Gray WA, Block PC, et al. Percutaneous Left Atrial Appendage Transcatheter Occlusion (PLAATO System) to prevent stroke in high-risk patients with non-rheumatic atrial fibrillation: results from the International Multi-Center Feasibility Trials. $J$ Am Coll Cardiol. 2005;46:9-14.

19. Heist EK, Refaat M, Danik SB, Holmvang G, Ruskin JN, Mansour M. Analysis of the left atrial appendage by magnetic resonance angiography in patients with atrial fibrillation. Heart Rhythm. 2006;3:1313-8. 